\title{
A Cohort Study on Raynaud's Phenomenon in Workers Exposed to Low Level Hand-Arm Vibration
}

\author{
Kotaro Tomida, Nobuyuki Miyai, Hiroichi Yamamoto, Seyed Mohamad Mirbod, \\ Tian-Kui Wang, Shunji Sakaguchi, Ikuharu Morioka and Kazuhisa MiYashita \\ Department of Hygiene, School of Medicine, Wakayama Medical University
}

\begin{abstract}
A Cohort Study on Raynaud's Phenomenon in Workers Exposed to Low Level Hand-Arm Vibration: Kotaro TomIDA, et al. Department of Hygiene, School of Medicine, Wakayama Medical University-To clarify the incidence of Raynaud's phenomenon among workers exposed to low level hand-arm vibration for a long time, a sample cohort of workers mainly operating a bush cleaner (the vibration level was $2-4 \mathrm{~m} / \mathrm{s}^{2} \mathrm{rms}$ ) were followed up for a period of $20 \mathrm{yr}$. The sample cohort consisted of 331 male workers mainly working at maintaining public roads or afforesting and gardening on a farm. The examination was based on questionnaires used in special medical examinations for vibration syndrome from 1977 to 1996. Raynaud's phenomenon was observed in 11 subjects. The accumulative occurrence rate increased linearly in the case of more than 11 operating years. The mean number of operating years at the occurrence of Raynaud's phenomenon was $11.7 \pm 7.1 \mathrm{yr}$. The mean total operating time at the occurrence of Raynaud's phenomenon was $3,756 \mathrm{~h}$ on the geometric average. Stockholm Workshop scale classified 1 subject as Stage 1 (mild), 4 subjects Stage 2 (moderate) and 6 subjects Stage 3 (severe). By the person-year method, the incidence of Raynaud's phenomenon was 4.48 per 1000 person-year. These findings show that the number of operating years for a bush cleaner should be considered to prevent Raynaud's phenomenon, even though the hand-arm vibration level is low. (J Occup Health 2000; 42: 292-296)
\end{abstract}

Key words: Cohort study, Raynaud's phenomenon, Hand-arm vibration, Person-year method

In recent years, the work control against exposure to hand-arm vibration has well been established and thereby

Received Feb 7, 2000; Accepted Aug 6, 2000

Correspondence to: $K$. Tomida, Department of Hygiene, School of Medicine. Wakavama Medical University, 811-1 Kimiidera, Wakayama 641-8509, Japan exposure time to hand-arm vibration has been decreased Vibrating tools have been improved and the exposure level has been decreasing'), but exposure to low level hand-arm vibration has induced long-term exposure to hand-arm vibration in workers operating vibrating tools. Under such conditions of the long-term exposure to low level hand-arm vibration, the occurrence of Raynaud's phenomenon has not yet been examined sufficiently.

We have given special medical examinations for vibration syndrome for a long time to workers mainly operating bush cleaners. The exposure level of a bush cleaner seemed to be much lower than that of a chain saw, but a bush cleaner can also cause Raynaud's phenomenon in operators. In this study, a sample cohort of workers mainly operating bush cleaners were followed up for a period of $20 \mathrm{yr}$ to clarify the occurrence of Raynaud's phenomenon in workers exposed to low level hand-arm vibration for a long time.

\section{Subjects and Methods}

The subjects were male public service workers in Wakayama Prefecture. They were mainly working to maintain keeping public roads or afforesting and gardening on a farm, and were using hand vibrating tools such as bush cleaners. The subjects in the subject group were 331 workers who took special medical examinations for vibration syndrome each winter for $20 \mathrm{yr}$ from 1977 to 1996.

Subjects in the control group were 425 male workers in a factory who did not use a vibrating tool and took annual health examinations from 1977 to 1996.

Special medical examinations for vibration syndrome consist of a primary medical examination and a secondary medical examination (Japanese labour standards bureau notification, No. 609 $)^{2}$. A cold provocation test with the $10^{\circ} \mathrm{C}$ for $10 \mathrm{~min}$ method is adopted to decrease pain and discomfort in patients from that in the $5^{\circ} \mathrm{C}$ for $10 \mathrm{~min}$ method. In this study, a questionnaire on working careers and physical examinations of the examinees was used as 
private data for the subjects. "Working career" means not only the number of years spent to working to maintain public roads or afforesting and gardening on a farm, but also the various kinds of vibrating tools used and the number of years, months a year and hours a day spent operating vibrating tools. "Physical examinations" involves a primary examination and a secondary examination to determine peripheral circulatory disturbances, peripheral nerve disturbances and motor disturbances.

The vibration level of the vibrating tools mainly used was identified from data sheets prepared by Tominaga et al. (personal communication).

In this study, a subject in subject group who was identified as having Raynaud's phenomenon at least in one finger on either hand or both hands was assigned to the Raynaud's phenomenon ( $R$ ) group. To identify Raynaud's phenomenon, a physician asked a subject in detail the site, the frequency and the factors inducing Raynaud's phenomenon. Furthermore, the physician confirmed the diagnosis of Raynaud's phenomenon by showing the subject a photograph of typical white finger. Subjects who had post-traumatic or primary Raynaud's phenomenon were excluded from the $\mathrm{R}$ group.

The number of years operating vibrating tools and the total operating time (TOT) at the time of occurrence of Raynaud's phenomenon were used as indices of the dose of exposure to hand-arm vibration of the subjects in the $\mathrm{R}$ group. The TOT was calculated from the product of three factors in the questionnaire on working careers: the number of years operating vibrating tools, annual number of operating days and number of operating hours in one day.

The stage of Raynaud's phenomenon in persons exposed to hand-arm vibration was classified by the Stockholm Workshop scale ${ }^{31}$. This new staging system has enabled us to define the stage score based on the number of affected fingers on each hand.

The person-year method was used to estimate the incidence of Raynaud's phenomenon in consideration of number of subjects and their individual observation periods. In this method one person-year is calculated for one person observed for one year during an observation period. This method is consequently independent of the length of the individual observation period for each subject and enables us to effectively use the data for both long-term observed subjects and short-term observed subjects, and to compare our results with those of the other group without considering the observation period.

\section{Results}

The number of examinees who took the special medical examinations for vibration syndrome in each year is shown in Table 1. It exceeded 150 from 1977 to 1981 , except for 1980. Since then the number has decreased to
Table 1. Annual trend in the number of examinees who took the special medical examinations for vibration syndrome during an observation period

\begin{tabular}{lc}
\hline Year & Number of examinees \\
\hline 1977 & 160 \\
1978 & 159 \\
1979 & 176 \\
1980 & 114 \\
1981 & 160 \\
1982 & 147 \\
1983 & 142 \\
1984 & 137 \\
1985 & 134 \\
1986 & 134 \\
1987 & 137 \\
1988 & 138 \\
1989 & 136 \\
1990 & 129 \\
1991 & 130 \\
1992 & 135 \\
1993 & 132 \\
1994 & 141 \\
1995 & 139 \\
1996 & 130 \\
\hline &
\end{tabular}

Table 2. Age composition of subject and control groups at the end of the observation period

\begin{tabular}{ccr}
\hline \multirow{2}{*}{$\begin{array}{c}\text { Age composition } \\
\text { (yr) }\end{array}$} & \multicolumn{2}{c}{ Number of subjects (\%) } \\
\cline { 2 - 3 } & Subject group & Control group \\
\hline $20-29$ & $15(11.5)$ & $115(27.1)$ \\
$30-39$ & $37(28.5)$ & $82(19.3)$ \\
$40-49$ & $33(25.4)$ & $178(41.9)$ \\
$50-59$ & $25(19.2)$ & $49(11.5)$ \\
$60-69$ & $20(15.4)$ & $18(0.2)$ \\
\hline
\end{tabular}

between 130 and 140 .

The age composition was calculated for the examinees in the year 1977, the beginning of the observation, 1986. the midterm observation period, and 1996, the end of the observation. In 1977, the majority of the examinees were in their forties $(36.9 \%)$. Next were those in their fifties $(36.3 \%)$. In 1986 , the examinees in their fifties were a majority $(43.3 \%)$. Next were those in their forties $(19.4 \%)$. In 1996 , the majority of examinee were in their thirties $(28.5 \%)$ and next those in their forties $(25.4 \%)$.

The age composition of the subject group was compared with the control group at the end of the observation period (Table 2). The mean age and standard 
Table 3. Vibrating tools, frequencies (\%), and mean operating days and times of subject group

\begin{tabular}{lccc}
\hline Vibrating tools & Number of subjects $(\%)$ & Operating days/year & Operating hours/day \\
\hline Bush cleaner & $309(94.2)$ & $66.9 \pm 45.1$ & $3.3 \pm 2.3$ \\
Rock drill & $58(17.7)$ & $19.9 \pm 24.4$ & $1.9 \pm 1.3$ \\
Chain saw & $47(14.3)$ & $35.9 \pm 41.8$ & $3.0 \pm 1.3$ \\
Tamper & $31(9.5)$ & $48.5 \pm 42.9$ & $1.4 \pm 0.8$ \\
Others & $42(14.6)$ & $32.1 \pm 27.5$ & $2.4 \pm 1.6$
\end{tabular}

Values are means \pm standard deviation.

Table 4. Vibration acceleration level of some types of bush cleaners

\begin{tabular}{ccc}
\hline Type & $\begin{array}{c}\text { Vibration acceleration } \\
\text { level }\left(\mathrm{m} / \mathrm{s}^{2} \mathrm{rms}\right)\end{array}$ & $\begin{array}{c}\text { Published year } \\
(\mathrm{yr})\end{array}$ \\
\hline A & 3.8 & 1980 \\
B & 3.5 & 1981 \\
C & 3.4 & 1982 \\
D & 2.6 & 1991 \\
E & 2.1 & 1996 \\
\hline Mean ( \pm S.D. $)$ & $3.1 \pm 0.7$ & \\
\hline
\end{tabular}

S.D. = standard deviation.

deviation was $44.4 \pm 11.8 \mathrm{yr}$ of age in the subject group and $38.6 \pm 10.0 \mathrm{yr}$ of age in the control group.

Analysis of the kinds of vibrating tools showed that those in the subject group used an average of $1.5 \mathrm{kinds}$ of vibrating tools and that 309 subjects (94.2\%) used a bush cleaner (Table 3 ). The vibration acceleration level of bush cleaners that the subjects had been using was estimated from data confirmed by Tominaga et al. (Table 4). The vibration level of bush cleaners was $2-4 \mathrm{~m} / \mathrm{s}^{2} \mathrm{mms}$.

The occurrence of Raynaud's phenomenon was observed in 22 in the subject group during the observation period. Eight subjects already had Raynaud's phenomenon at the start of the observation period. To select subjects at risk of Raynaud's phenomenon, two subjects with traumatic Raynaud's phenomenon and a subject with primary Raynaud's phenomenon were excluded. Consequently, the $\mathrm{R}$ group consisted of 11 subjects. The mean age at the start of operating the vibrating tools was $40.5 \pm 10.9 \mathrm{yr}$.

The distribution of the number of operating years at the time of occurrence of Raynaud's phenomenon is shown in Fig. 1. The majority of operating years were between 20 and 22 yr ( 3 subjects). Next were between 6 and $8 \mathrm{yr}$ and between 8 and $10 \mathrm{yr}$ ( 2 subjects in each). The mean number of operating years at the time of occurrence of Raynaud's phenomenon was $11.7 \pm 7.1$ yr.

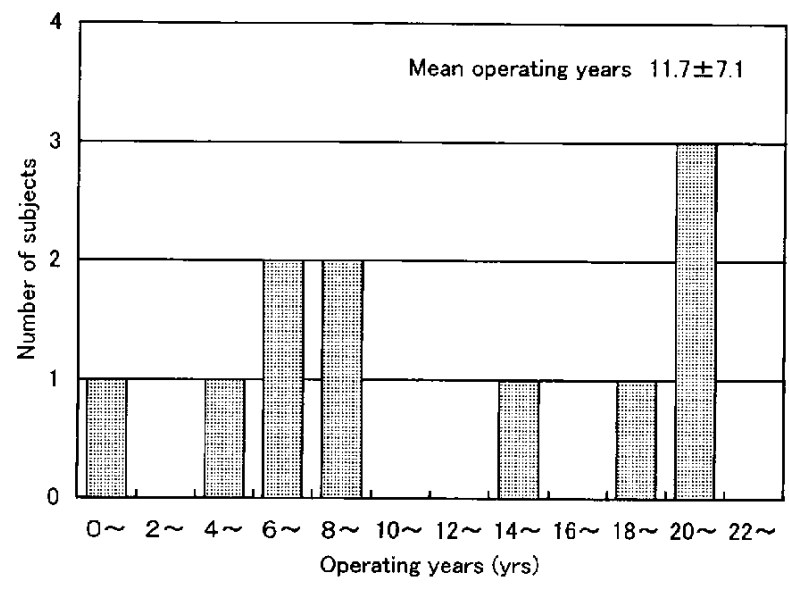

Fig. 1. Distribution of number of operating years at the time of occurrence of Raynaud's phenomenon in R group.

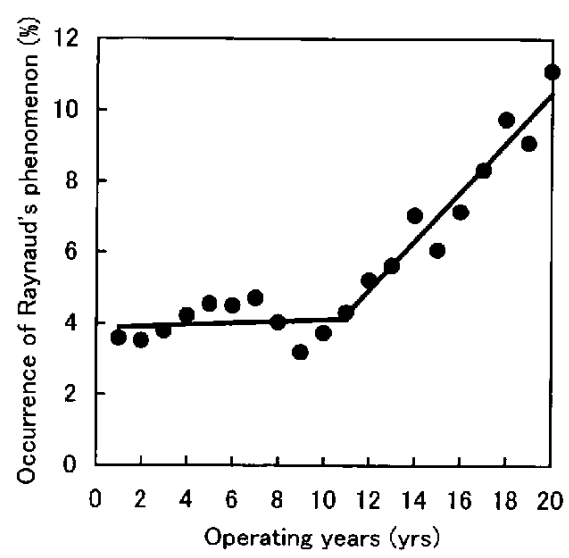

Fig. 2. Accumulative occurrence rate of Raynaud's phenomenon by operating years in subject group.

The accumulative occurrence rate of Raynaud's phenomenon in the subject group during the observation period is shown in Fig. 2. During the observation period, the accumulative occurrence rate of Raynaud's phenomenon by operating years was computed at from 1 


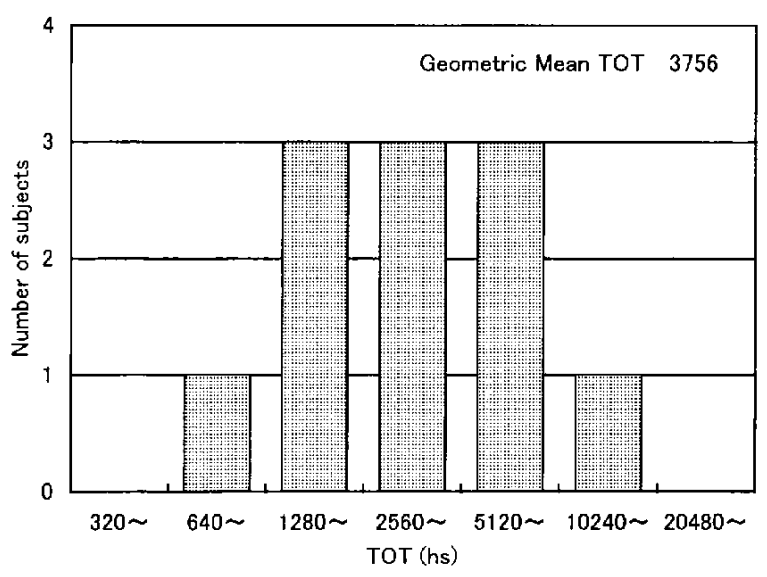

Fig. 3. Distribution of the TOT at the time of occurrence of Raynaud's phenomenon in $\mathrm{R}$ group.

to 20 operating years. The accumulative occurrence rate increased linearly in the case of more than 11 operating years.

The distribution of TOT at the time of occurrence of Raynaud's phenomenon is shown in Fig. 3. The majority of TOT was between $1,280 \mathrm{~h}$ and $2,560 \mathrm{~h}$, between 2,560 $\mathrm{h}$ and $5,120 \mathrm{~h}$ and between $5,120 \mathrm{~h}$ and $10,240 \mathrm{~h}$ (3 subjects in each). The mean TOT at the time of occurrence of Raynaud's phenomenon in the R group was $3,756 \mathrm{~h}$ on the geometric average.

The distribution of the number of operating years by the age group at the time of occurrence of Raynaud's phenomenon in $\mathrm{R}$ group was computed. The number of operating years for the subjects in their fifties was the greatest, and the average was 18.0 yr $(n=3)$. Next were those in their sixties, at $14.5 \mathrm{yr}(\mathrm{n}=2)$. The number of operating years was fewer in the thirties age group (7.5 $\mathrm{yr}, \mathrm{n}=2)$, then forties $(8.0 \mathrm{yr}, \mathrm{n}=3)$ and seventies $(8.0 \mathrm{yr}$, $\mathrm{n}=1$ ).

On the Stockholm Workshop scale, one subject in the $R$ group was classified into Stage 1 (mild), 4 subjects into stage 2 (moderate) and 6 subjects into Stage 3 (severe). Three of 6 subjects in Stage 3 showed signs of Raynaud's phenomenon in all fingers on both hands. In the control group, two subjects were found to have Raynaud's phenomenon. They were at Stage 1 and Stage 3. We adopted the most severe stage of Raynaud's phenomenon identified during the individual observation period for classifying the stage of Raynaud's phenomenon.

Figure 4 shows the year when the subjects took the special medical examinations and the year when they were found to have Raynaud's phenomenon during the observation period. The total observation person year of 320 subjects in the subject group were 2454.5 , in which the incidence of Raynaud's phenomenon was 4.48 (per

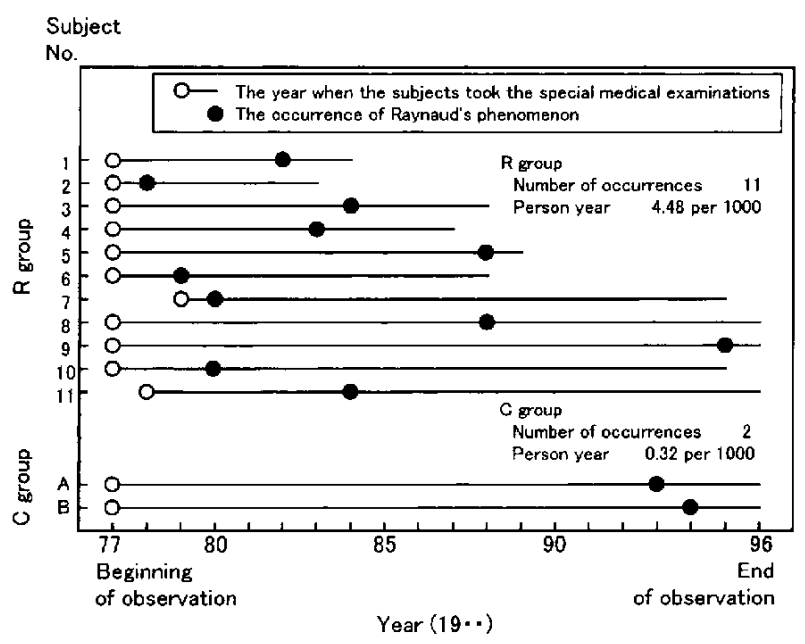

Fig. 4. Annual trend in the occurrence of Raynaud's phenomenon during the observation period in $\mathrm{R}$ and control (C) groups.

1000 person-year). The total observation person year of 425 subjects in the control group was 6311.5 , and the incidence of Raynaud's phenomenon was 0.32 (per 1000 person-year).

\section{Discussion}

This study made it clear that the exposure to even low level hand-arm vibration is also able to cause Raynaud's phenomenon in the workers operating bush cleaners for a long time.

The subjects of this study mainly used bush cleaners. The vibration acceleration levels of the bush cleaners were about $3.5 \mathrm{~m} / \mathrm{s}^{2} \mathrm{rms}$ in the early 1980s. Vibration acceleration levels were decreasing year by year to about $2.5 \mathrm{~m} / \mathrm{s}^{2} \mathrm{rms}$ in the late $1990 \mathrm{~s}$. Even in the early $1980 \mathrm{~s}$ the vibration acceleration level was much lower than that of a chain saw (about $15 \mathrm{~m} / \mathrm{s}^{2} \mathrm{rms}$ ), so that the level of exposure to hand-arm vibration was lower in the subject group in this study than in workers mainly operating a chain saw.

Futatsuka et $\mathrm{al}^{4}{ }^{4}$ reported the actual conditions in which Raynaud's phenomenon occurred in forestry workers who mainly operated a chain saw. The rate of prevalence of Raynaud's phenomenon reached a plateau at 5 yr after beginning chain saw use since 1965 , suggesting that the number of years operating of a chain saw at the time of occurrence of Raynaud's phenomenon was less than $5 \mathrm{yr}$ in most subjects. In our results for the $\mathrm{R}$ group, the number of years operating a bush cleaner at the time of occurrence of Raynaud's phenomenon was 5 to $10 \mathrm{yr}$ in 53 percent of the subjects and was $10 \mathrm{yr}$ or more in 37 percent of the subjects. This shows that a bush cleaner induces Raynaud's phenomenon during a comparatively long period. 
There is much cross sectional research on Raynaud's phenomenon resulting from operating various kinds of vibrating tools. The occurrence of Raynaud's phenomenon depends on the kinds of vibrating tools. The prevalence of Raynaud's phenomenon was $1.0-2.3 \%$ among workers mainly operating a bush cleaner ${ }^{5,6}$. This study showed that we could find 0.45 subjects with Raynaud's phenomenon if we could observe 100 subjects for a year. That makes the incidence $0.45 \%$ and it corresponds to or is lower than that in former results. In this study, the incidence of Raynaud's phenomenon in the $\mathrm{R}$ group was apparently higher than that in the $\mathrm{C}$ group. This is due to the effect of exposure to hand-arm vibration. It is noted that a cold environment and working format may be factors inducing Raynaud's phenomenon. Since subjects in the $\mathrm{C}$ group work inside the factory, the working environment and working format of the $\mathrm{C}$ group are different from those of the $\mathbf{R}$ group. Therefore, further discussion on the contribution of these factors to the incidence of Raynaud's phenomenon is needed.

The committee on vibration syndrome in the Japan Society for Occupational Health reported that the using a vibrating tool of which rms frequency weighted acceleration for $4 \mathrm{~h}$ was $3.2 \mathrm{~m} / \mathrm{s}^{2} \mathrm{rms}^{7}$, induced the incidence of Raynaud's phenomenon in $5 \%$ after $10 \mathrm{yr}$ and in $12.8 \%$ after $16 \mathrm{yr}$. In this study, the subjects used a bush cleaner of which rms frequency weighted acceleration was $3.1 \mathrm{~m} / \mathrm{s}^{2} \mathrm{rms}$ for $3.3 \mathrm{~h}$ a day. The rms frequency weighted acceleration for $4 \mathrm{~h}$ in the subject group becomes $2.8 \mathrm{~m} / \mathrm{s}^{2} \mathrm{rms}$, so that if 100 subjects in the subject group had used the bush cleaner under such conditions, the incidence of Raynaud's phenomenon would have become $4.5 \%$ for $10 \mathrm{yr}$ and $7.2 \%$ for $16 \mathrm{yr}$. These results correspond to or are lower than those in the report from the committee on vibration syndrome.

In conclusion, this study notes that operating a bush cleaner for a long time causes the Raynaud's phenomenon (in 4.5 subjects after following up 100 subjects for 10 $y r$ ). The findings support the provisional occupational exposure limits for hand-arm vibration suggested by the
Japan Society for Occupational Health. The findings also contribute to health management for long-term exposure to low level hand-arm vibration. The preventive countermeasures for Raynaud's phenomenon in workers operating low level vibrating tools should be based on such a long-term observation as in this study.

Acknowledgments: This report was financed by a TrustGrant from the Japanese Ministry of Labour for scientific research on accidents (1998).

\section{References}

1) Suzuki H, Iwasaki S. Effects of the reduction of vibration intensity of chain saws on the prevalence rates of vibration syndrome among forestry workers. Jpn J Ind Health 1990; 32: 18-25 (in Japanese).

2) Japanese Ministry of Labour. The procedure of a special medical examination related to workers handling vibrating tools. Japanese Labour Standards Bureau Notification 1975; No. 609 (in Japanese).

3) Gemne G, Pyykko I, Taylor W, Pelmear PL. The Stockholm Workshop scale for the classification of cold-induced Raynaud's phenomenon in the hand-arm vibration syndrome (revision of the Taylor-Pelmear scale), Scand J Work Environ Health 1987; 13: 275 278.

4) Futatsuka M, Takamatsu M, Goto T. An epidemiologic study on vibration hazards among workers at the state forests in Kyushu. Jpn J Ind Health 1976; 18: 3-10 (in Japanese).

5) Watanabe $S$, Abe $S$. Local vibration disease of chain saw and bush cleaner operators. Jpn J Ind Health 1966; 8: 168 (in Japanese).

6) Futatsuka M. Studies on Vibration hazards due to chain saw. Kumamoto Igakukai Zasshi 1969; 43: 467-524 (in Japanese).

7) Japan Society for Occupational Health. Recommendation of occupational exposure limits. $\mathrm{X}$. Occupational exposure limits for hand-arm vibration (Provisional)-. San Ei Shi 1999; 41: 115-117 (in Japanese). 